\title{
Pencil Beam Spectral Measurements of Ce, Ho, Yb, and Ba Powders for Potential Use in Medical Applications
}

\author{
N. Martini, ${ }^{1}$ V. Koukou, ${ }^{1}$ C. Michail, ${ }^{2}$ P. Sotiropoulou, ${ }^{1}$ N. Kalyvas, ${ }^{2}$ \\ I. Kandarakis, ${ }^{2}$ G. Nikiforidis, ${ }^{1}$ and G. Fountos ${ }^{2}$ \\ ${ }^{1}$ Department of Medical Physics, Medical School, University of Patras, Rion, 26500 Patras, Greece \\ ${ }^{2}$ Radiation Physics, Materials Technology and Biomedical Imaging Laboratory, Department of Biomedical Engineering, \\ Technological Educational Institute of Athens, Egaleo, 12210 Athens, Greece
}

Correspondence should be addressed to I. Kandarakis; kandarakis@teiath.gr

Received 29 October 2014; Revised 19 December 2014; Accepted 19 December 2014

Academic Editor: Eugen Culea

Copyright (c) 2015 N. Martini et al. This is an open access article distributed under the Creative Commons Attribution License, which permits unrestricted use, distribution, and reproduction in any medium, provided the original work is properly cited.

\begin{abstract}
The aim of the present study was to obtain modified X-ray spectra, by using appropriate filter materials for use in applications such as dual energy X-ray imaging. K-edge filtering technique was implemented in order to obtain narrow energy bands for both dual- and single-kVp techniques. Three lanthanide filters (cerium, holmium, and ytterbium) and a filter outside lanthanides (barium), with low K-edge, were used to modify the X-ray spectra. The X-ray energies that were used in this work ranged from 60 to $100 \mathrm{kVp}$. Relative root mean square error (RMSE) and the coefficient of variation were used for filter selection. The increasing filter thicknesses led to narrower energy bands. For the dual-kVp technique, $0.7916 \mathrm{~g} / \mathrm{cm}^{2} \mathrm{Ho}, 0.9422 \mathrm{~g} / \mathrm{cm}^{2} \mathrm{Yb}$, and $1.0095 \mathrm{~g} / \mathrm{cm}^{2} \mathrm{Yb}$ were selected for 70,80 , and $90 \mathrm{kVp}$, respectively. For the single-kVp technique $0.5991 \mathrm{~g} / \mathrm{cm}^{2} \mathrm{Ce}, 0.8750 \mathrm{~g} / \mathrm{cm}^{2} \mathrm{Ba}$, and $0.8654 \mathrm{~g} / \mathrm{cm}^{2}$ Ce were selected for 80,90 , and $100 \mathrm{kVp}$, respectively. The filtered X-ray spectra of this work, after appropriate modification, could be used in various $\mathrm{X}$-ray applications, such as dual-energy mammography, bone absorptiometry, and digital tomosynthesis.
\end{abstract}

\section{Introduction}

The photon spectrum from a conventional X-ray tube consists of a broadband of energies [1]. In dual energy medical applications, a low- and a high-energy band are required [26]. In order to resolve the broadband spectrum into low- and high-energy bands, the following three methods can be used: (i) K-edge filtering [7, 8], (ii) $\mathrm{kVp}$ switching $[9,10]$, and (iii) the combination of both $[8,11]$.

In single- $\mathrm{kVp}$ techniques, only a single exposure is required with K-edge filtering for both energies to be present simultaneously in the radiation beam. Selective attenuation of photons, just above the absorption edge, creates a transmitted spectrum consisting of two relatively narrow energy bands after heavy filtration [12]. Single-kVp techniques are used in quantitative measurements such as bone densitometry.

Dual-kVp techniques employ two sequential measurements at different kilovoltages, typically with different filters between exposures. In this technique, K-edge filtering is used to remove selectively energy photons, above the Kedge, from the spectra, while lower-energy photons are also diminished due to their low penetrability. When K-edge filters are applied, narrower spectra are obtained compared with the spectra filtered with conventional filters. The use of $\mathrm{K}$-edge lanthanide filtering in dual-kVp technique for the narrowing of the low-energy peak was suggested initially by Rutt [8]. The narrowing of the low $\mathrm{kV}$-spectrum results in greater separability between the two peaks in spectra as well as decrease of beam hardening effects. Gustafsson et al. [11] suggested the use of K-edge lanthanide filter for both the lowand high-energy exposures to narrow both the low- and high$\mathrm{keV}$ peaks in spectra. Simulation studies indicated that Kedge filtered spectra could be used to various X-ray applications, such as dual energy mammography, X-ray computed mammotomography (dual-kVp), and bone densitometry (single-kVp) [4-6, 13-15]. Several semiconductor detectors have been proposed for X-ray spectra measurements under clinical conditions [16-22]. 
TABLE 1: Areal density ranges of the used substances and the corresponding elements.

\begin{tabular}{|c|c|c|c|c|c|}
\hline Substance & $\begin{array}{l}\text { Substance areal density } \\
\left(\mathrm{g} / \mathrm{cm}^{2}\right)\end{array}$ & $\begin{array}{l}\text { Element areal density } \\
\left(\mathrm{g} / \mathrm{cm}^{2}\right)\end{array}$ & $\begin{array}{l}\text { Element density } \\
\left(\mathrm{g} / \mathrm{cm}^{3}\right)\end{array}$ & $\begin{array}{l}\text { Element thickness } \\
(\mu \mathrm{m})\end{array}$ & Value layers \\
\hline $\mathrm{BaCl}_{2}\left(\mathrm{H}_{2} \mathrm{O}\right)_{2}$ & $0.6224-1.5561$ & $0.3500-0.8750$ & 3.500 & $1000-2500$ & $162-793$ \\
\hline $\mathrm{CeO}_{2}$ & $0.0818-2.0443$ & $0.0665-1.6643$ & 6.657 & $100-2500$ & $67-238$ \\
\hline $\mathrm{Ho}_{2} \mathrm{O}_{3}$ & $0.5037-1.5112$ & $0.4398-1.3193$ & 8.795 & $500-1500$ & $75-399$ \\
\hline $\mathrm{Yb}_{2} \mathrm{O}_{3}$ & $0.3832-1.1495$ & $0.3365-1.0095$ & 6.730 & $500-1500$ & $76-178$ \\
\hline
\end{tabular}

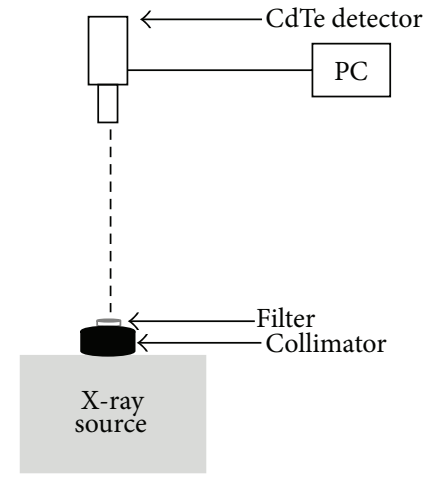

FIGURE 1: The set-up used for the spectra measurement.

In this paper, $\mathrm{X}$-ray spectra filtered with several different powder filter materials were measured. A pencil beam was used, as the cone beam depends on the size and the position of the filter, as well as the broadening of the beam. In addition, when pencil beam is used, the divergence of the linear attenuation coefficient is minimized. A cadmium telluride (CdTe) energy discriminating and counting detector was used. K-edge filtering technique was implemented in order to obtain narrow energy bands, for both dual- and single$\mathrm{kVp}$ techniques. The spectra presented here for the dual$\mathrm{kVp}$ technique can be used in imaging techniques such as $\mathrm{X}$-ray mammography, computed mammotomography, and angiography, while the spectra for the single-kVp technique can be used in bone densitometry for bone characterization.

\section{Materials and Methods}

X-ray spectroscopy was performed by measuring spectra from a tungsten (W) anode Norland XR-46 (Norland Medical Systems Inc., Fort Atkinson, WI). The tube voltage ranges from 60 to $100 \mathrm{kV}$. Five separate X-ray tube operating voltages, from 60 to $100 \mathrm{kVp}$, in $10 \mathrm{kV}$ increments were investigated. The collimation applied was the standard collimation employed by Norland for dual energy X-ray absorptiometry (DEXA) applications. The divergence at a distance of $20.5 \mathrm{~cm}$ was $4 \mathrm{~mm}$. The samarium (Sm) filter employed by Norland was extracted and replaced with the filters used in this study. Figure 1 shows the set-up used for the measurement of the spectra.

For the K-edge technique, barium (Ba), cerium $(\mathrm{Ce})$, holmium (Ho), and ytterbium (Yb) were used, with their K-edge energies ranging from 37.44 to $61.33 \mathrm{keV}$. The Ce, $\mathrm{Ho}$, and $\mathrm{Yb}$ filters were selected since they cover almost the
TABLE 2: Substances, kVp range, and exposure techniques used.

\begin{tabular}{lcc}
\hline Substance & $\mathrm{kVp}$ & Technique \\
\hline $\mathrm{BaCl}_{2}\left(\mathrm{H}_{2} \mathrm{O}\right)_{2}$ & $80-100$ & Single-kVp \\
$\mathrm{CeO}_{2}$ & $60-100$ & Dual- and single-kVp \\
$\mathrm{Ho}_{2} \mathrm{O}_{3}$ & $70-90$ & Dual-kVp \\
$\mathrm{Yb}_{2} \mathrm{O}_{3}$ & $70-90$ & Dual-kVp \\
\hline
\end{tabular}

whole atomic number $(Z)$ range of lanthanides. The Ba filter material was, also, selected as an element outside lanthanides due to its lower K-edge. Elements with lower K-edge than $\mathrm{Ba}$ were not selected since they are eliminating the number of total counts in the low-energy peak in X-ray spectra. For the filtration with $\mathrm{Ba}, \mathrm{Ce}, \mathrm{Ho}$, and $\mathrm{Yb}$, barium chloride dihydrate ( $\left.\mathrm{BaCl}_{2}\left(\mathrm{H}_{2} \mathrm{O}\right)_{2}\right)$ (Mallinckrodt, 10326-17-9), cerium(IV) oxide $\left(\mathrm{CeO}_{2}\right)$ (Alfa Aesar, 44656, 99\% purity), holmium(III) oxide $\left(\mathrm{Ho}_{2} \mathrm{O}_{3}\right)$ (Sigma-Aldrich, H9750-10G, 99.9\% purity), and ytterbium(III) oxide $\left(\mathrm{Yb}_{2} \mathrm{O}_{3}\right)$ (Sigma-Aldrich, 246999-50G, 99\% purity) powders were used, respectively. The areal densities of the substances ranged from 0.0818 to $2.0443 \mathrm{~g} / \mathrm{cm}^{2}$ corresponding to element $(\mathrm{Ba}, \mathrm{Ce}, \mathrm{Ho}$, and $\mathrm{Yb}$ ) thicknesses from 100 to $2500 \mu \mathrm{m}$, respectively (Table 1 ). The powders were prepared, by a mixture with pure carbon (7\%) powder, in the form of $13 \mathrm{~mm}$ diameter discs (Figure 1), using an infrared spectroscopy hydraulic pellet press, by applying compression of 14 tons for $10 \mathrm{~min}$. The mixture of the powders with the carbon was accomplished in order for the materials to be consistent. The acquisition parameters are summarized in Table 2. All the measurements had $5 \mathrm{~min}$ acquisition time. In the dual-kVp technique, Ce was used for the low energy and $\mathrm{Ho}$ and $\mathrm{Yb}$ were used for the high energy, while $\mathrm{Ba}$ and $\mathrm{Ce}$ filters were used for the single-kVp technique.

The X-ray energy discriminating and counting detector system that was used for the spectroscopy measurements was a portable cadmium telluride (CdTe) detector (AMPTEK XR100T) [23-26]. The CdTe detector was connected to a digital processor (PX4 Digital Pulse Processor), including three major components: (i) a high performance shaping amplifier, (ii) a multichannel analyzer (MCA), and (iii) power supplies. The detector was calibrated for energy scales, linearity checks, and energy resolution, by using ${ }^{125} \mathrm{I}(35 \mathrm{keV})$ and ${ }^{99 \mathrm{~m}} \mathrm{TC} \gamma$ ray $(140.6 \mathrm{keV})$ calibration sources. The source to detector distance (SDD) was $47.5 \mathrm{~cm}$.

The measured spectra were corrected for both efficiency and dead time of the PX4 multichannel analyzer in order to determine the incident photons on the detector surface. The efficiency of the XR-100CdTe results from the product 
of the probability of transmission through beryllium (Be) window and the probability of the photon interactions within the active area of the CdTe detector. The data provided by the manufacturer were used for the detector efficiency corrections [27].

For all corrected measured spectra, relative root mean square error $\left(\mathrm{RMSE}_{\text {rel }}\right)$ was calculated as an indicative parameter of spectral energy bandwidth. The RMSE $\mathrm{rel}_{\text {rel }}$ was used as a metric of the narrowing of the spectrum, since it calculates the divergence between values and in this case each energy, of the spectrum, from the corresponding mean energy [28]. $\mathrm{RMSE}_{\text {rel }}$ can be expressed as

$$
\mathrm{RMSE}_{\mathrm{rel}}=\sqrt{\frac{\sum_{E_{\min }}^{E_{\max }} \Phi\left(E_{i}\right)\left(E_{i}-\bar{E}\right)^{2}}{\sum_{E_{\min }}^{E_{\max }} \Phi\left(E_{i}\right) E_{i}}},
$$

where $\Phi\left(E_{i}\right)$ are the photons at each energy, $E_{i}$ is the energy (keV), and $\bar{E}$ is the mean energy of the spectrum (keV).

The filters and the thickness range were chosen in order to fulfill both of the following criteria: (a) the narrowing of the energy band of the spectrum quantitated by $\mathrm{RMSE}_{\text {rel }}$ and (b) the total number of photons in spectrum to exceed $10^{6}$. When the total number of photons exceeds $10^{6}$, the coefficient of variation $(\mathrm{CV}(\%))$ in this measurement will be less than $0.1 \%$ since the photon detection considers Poisson distribution and $\mathrm{CV}(\%)$ was calculated from the following equation:

$$
\operatorname{CV}(\%)=\frac{\sqrt{\sum \Phi\left(E_{i}\right)}}{\sum \Phi\left(E_{i}\right)} \cdot 100,
$$

where $\Phi\left(E_{i}\right)$ are the photons at each energy $E_{i}$.

\section{Results and Discussion}

The results are presented as functions of the areal density of the corresponding element. Figure 2 shows measured spectra for $60 \mathrm{kVp}$, Ce filtered X-ray beam with areal densities of 0.4659 and $0.9319 \mathrm{~g} / \mathrm{cm}^{2}$, respectively. The $0.4659 \mathrm{~g} / \mathrm{cm}^{2} \mathrm{Ce}$ filtered spectrum is plotted with continuous line, whereas the corresponding $0.9319 \mathrm{~g} / \mathrm{cm}^{2}$ is plotted with dashed lines. As it can be seen from Figure 2, the spectrum shape is not changing significantly, when increasing areal density, while the number of photons decreased to about $40 \%$. Thicker filters reduce the number of lower-energy photons, while the high-energy photons are eliminated by the K-edge absorption [4-6]. Consequently, the mean energy of the filtered beam is concentrated around the K-edge of the filter material $[12,13]$.

Table 3 shows the RMSE rel and the CV(\%) for the Ho and Yb filters used in 70, 80, and $90 \mathrm{kVp}$. At $70 \mathrm{kVp}, 0.7916 \mathrm{~g} / \mathrm{cm}^{2}$ $\mathrm{Ho}$ and $0.8076 \mathrm{~g} / \mathrm{cm}^{2} \mathrm{Yb}$ resulted in $\mathrm{CV}(\%)$ approximately $0.1 \%$. The Ho filter was selected as it had lower RMSE compared with $\mathrm{Yb}(7.14 \%)$. At $80 \mathrm{kVp}, 0.7916 \mathrm{~g} / \mathrm{cm}^{2}$ Ho and $0.9422 \mathrm{~g} / \mathrm{cm}^{2} \mathrm{Yb}$ fulfilled the limitation of $\mathrm{CV}(\%)$. The $\mathrm{Yb}$ filter was selected as it resulted in $14.41 \%$ lower $\mathrm{RMSE}_{\text {rel }}$. Finally, at $90 \mathrm{kVp}, 0.8795 \mathrm{~g} / \mathrm{cm}^{2} \mathrm{Ho}$ and $1.0095 \mathrm{~g} / \mathrm{cm}^{2} \mathrm{Yb}$ resulted in $\mathrm{CV}(\%)$ approximately $0.1 \%$. However, the $\mathrm{Yb}$ had $37.74 \%$ lower $^{\mathrm{RMSE}}$ rel compared with the Ho. Figures 3, 4,
TABLE 3: Filters used in dual-kVp technique.

\begin{tabular}{lcccccc}
\hline & \multicolumn{2}{c}{$\begin{array}{c}\text { Areal density } \\
\left(\mathrm{g} / \mathrm{cm}^{2}\right)\end{array}$} & \multicolumn{2}{c}{$\mathrm{RMSE}_{\text {rel }}$} & \multicolumn{2}{c}{$\mathrm{CV}(\%)$} \\
$\mathrm{kVp}(\mathrm{keV})$ & $\mathrm{Ho}$ & $\mathrm{Yb}$ & $\mathrm{Ho}$ & $\mathrm{Yb}$ & Ho & $\mathrm{Yb}$ \\
\hline 70 & 0.7619 & 0.8076 & 0.0112 & 0.0120 & 0.1018 & 0.0980 \\
80 & 0.7619 & 0.9422 & 0.0118 & 0.0101 & 0.0931 & 0.1035 \\
90 & 0.8795 & 1.0095 & 0.0159 & 0.0099 & 0.1067 & 0.1035 \\
\hline
\end{tabular}

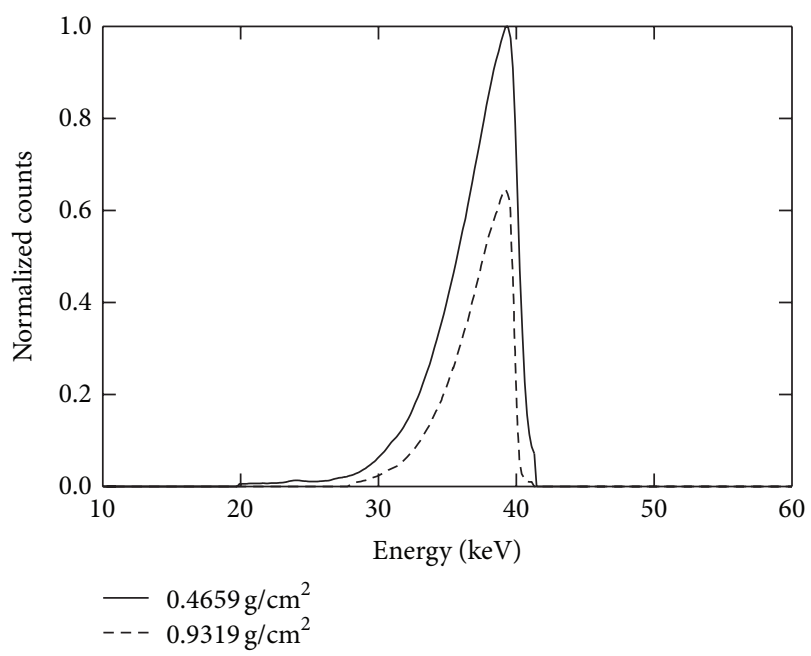

FIGURE 2: Low-energy spectrum at $60 \mathrm{kVp}$ filtered with 0.4659 and $0.9319 \mathrm{~g} / \mathrm{cm}^{2} \mathrm{Ce}(700$ and $1400 \mu \mathrm{m} \mathrm{Ce}$, resp.).

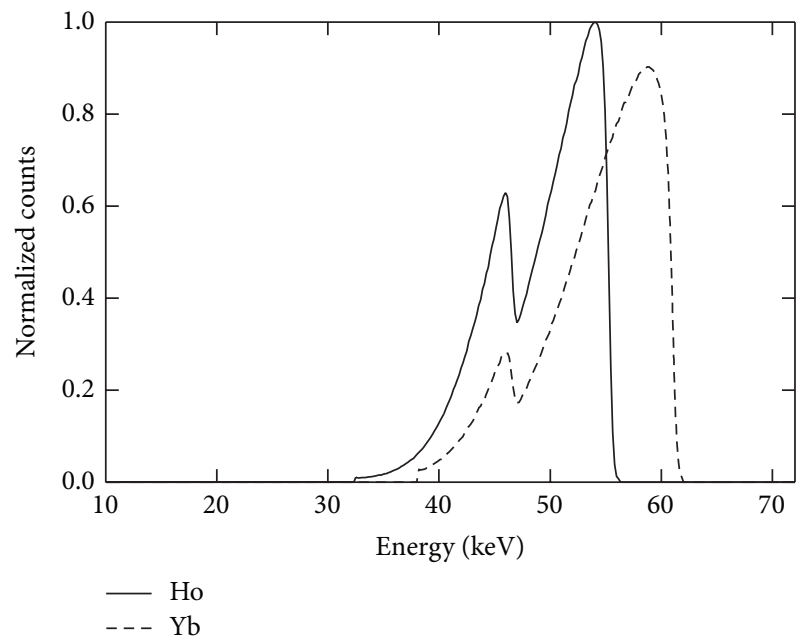

FIgURE 3: High-energy spectrum at $70 \mathrm{kVp}$ filtered with $0.7916 \mathrm{~g} / \mathrm{cm}^{2} \mathrm{Ho}$ and $0.8076 \mathrm{~g} / \mathrm{cm}^{2} \mathrm{Yb}(900 \mu \mathrm{m}$ Ho and $1200 \mu \mathrm{m}$ $\mathrm{Yb})$.

and 5 show the corresponding Ho and $\mathrm{Yb}$ filtered spectra at 70,80 , and $90 \mathrm{kVp}$, respectively. In Figures 3, 4, and 5, a small number of counts at energies over the K-edge were measured which are not visible in these plots. However, at $90 \mathrm{kVp} \mathrm{Ho}$ filtered spectrum (Figure 5), a number of counts at energies over the $\mathrm{K}$-edge are noticeable, since the $\mathrm{K}$ absorption edge of Ho is lower than that of Yb. In Table 4, the selected 


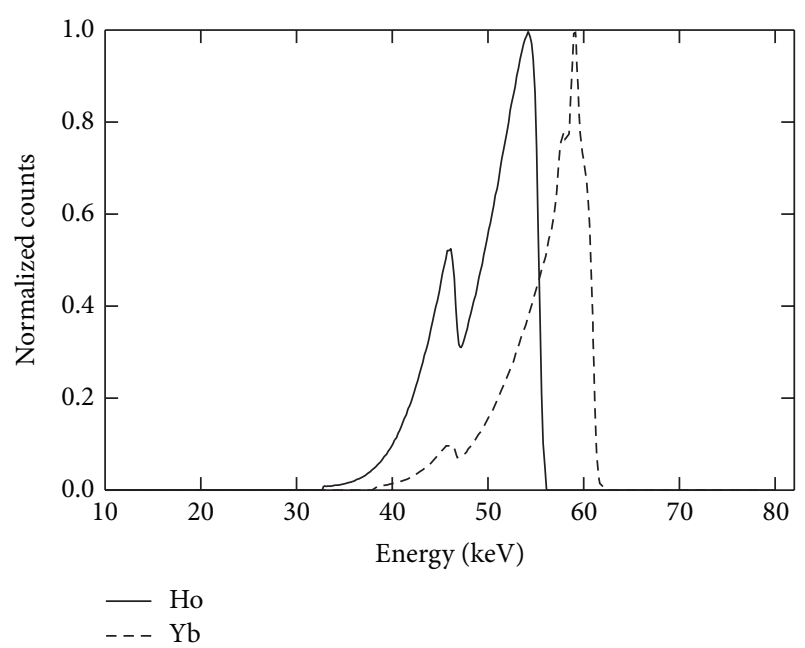

FIgURE 4: High-energy spectrum at $80 \mathrm{kVp}$ filtered with $0.7916 \mathrm{~g} / \mathrm{cm}^{2}$ Ho and $0.9422 \mathrm{~g} / \mathrm{cm}^{2} \mathrm{Yb}(900 \mu \mathrm{m}$ Ho and $1400 \mu \mathrm{m}$ $\mathrm{Yb})$.

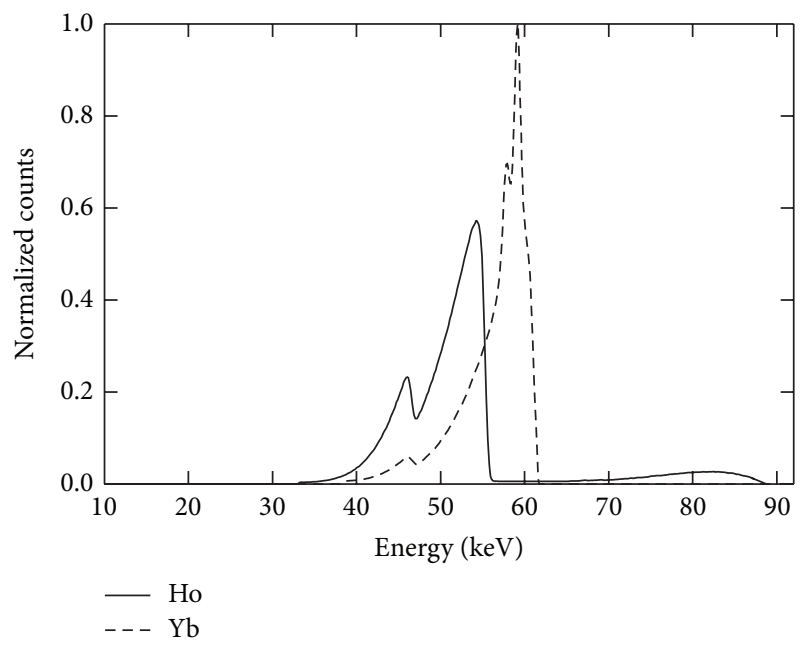

FIGURE 5: High-energy spectrum at $90 \mathrm{kVp}$ filtered with $0.8795 \mathrm{~g} / \mathrm{cm}^{2}$ Ho and $1.0095 \mathrm{~g} / \mathrm{cm}^{2} \mathrm{Yb}(1000 \mu \mathrm{m}$ Ho and $1500 \mu \mathrm{m}$ $\mathrm{Yb})$.

filters for dual-kVp technique at 70,80 , and $90 \mathrm{kVp}$ are shown. The mean energies, $\mathrm{ME}$, were calculated as $\mathrm{ME}=$ $\sum \Phi\left(E_{i}\right) E_{i} / \sum \Phi\left(E_{i}\right)$, where $\Phi\left(E_{i}\right)$ are the photons at each energy $E_{i}$, for energies from 30 to $65 \mathrm{keV}$.

Figure 6 shows an $80 \mathrm{kVp}$ X-ray spectrum filtered with $0.5991 \mathrm{~g} / \mathrm{cm}^{2} \mathrm{Ce}$ for the single-kVp technique. A comparison of the filtered beams, at $60 \mathrm{kVp}$ (Figure 2) and $80 \mathrm{kVp}$ (Figure 6), shows that the high-energy photons result in a bimodal shape of the spectrum, by allowing higher-energy photon to pass through [12-14].

Figure 7 shows a $90 \mathrm{kVp}$ spectrum filtered with $0.8750 \mathrm{~g} / \mathrm{cm}^{2} \mathrm{Ba}$. A sharp cutoff is evident in the detected photons at energies higher than the K-edge, leading to a spectrum with narrower energy bands. This spectrum, compared with a $0.8400 \mathrm{~g} / \mathrm{cm}^{2}$ Ba filtered spectrum, resulted in
TABLE 4: Mean and maximum energies for the selected dual-kVp filters.

\begin{tabular}{lcccc}
\hline $\begin{array}{l}\mathrm{kVp} \\
(\mathrm{keV})\end{array}$ & Element & $\begin{array}{c}\text { Areal density } \\
\left(\mathrm{g} / \mathrm{cm}^{2}\right)\end{array}$ & $\begin{array}{r}\text { Mean energy } \\
(\mathrm{keV})\end{array}$ & $\begin{array}{c}\text { Maximum energy } \\
(\mathrm{keV})\end{array}$ \\
\hline 70 & $\mathrm{Ho}$ & 0.7619 & 50.31 & 55 \\
80 & $\mathrm{Yb}$ & 0.9422 & 56.13 & 61 \\
90 & $\mathrm{Yb}$ & 1.0095 & 56.89 & 61 \\
\hline
\end{tabular}

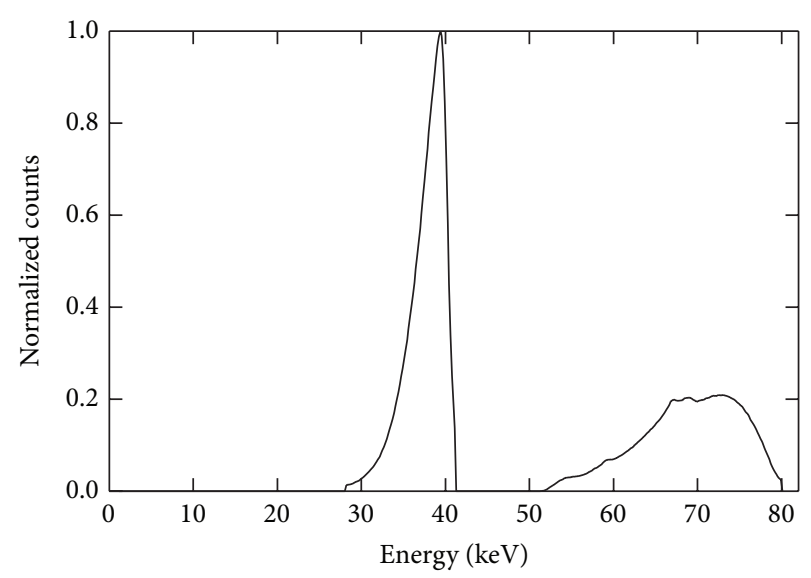

Figure 6: High-energy spectrum at $80 \mathrm{kVp}$ filtered with $0.5991 \mathrm{~g} / \mathrm{cm}^{2} \mathrm{Ce}(900 \mu \mathrm{m} \mathrm{Ce})$.

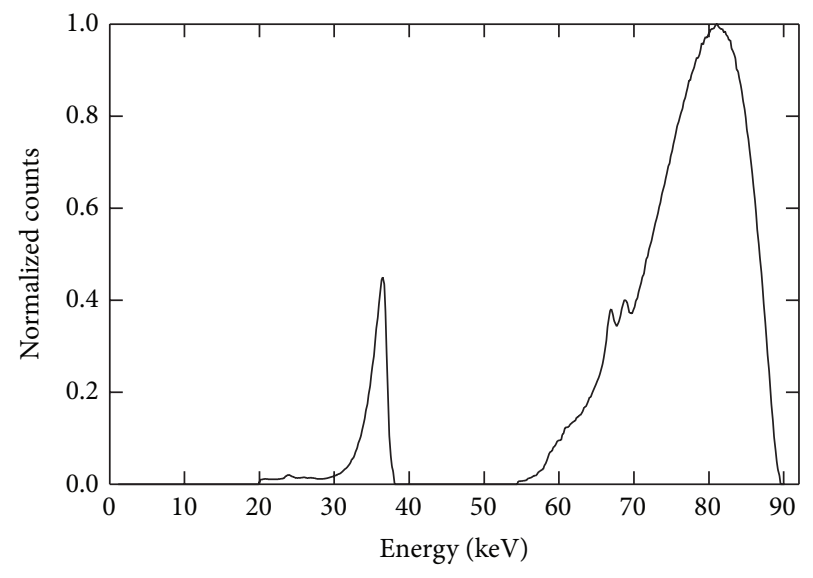

FIGURE 7: High-energy spectrum at $90 \mathrm{kVp}$ filtered with $0.8750 \mathrm{~g} / \mathrm{cm}^{2} \mathrm{Ba}(2500 \mu \mathrm{m} \mathrm{Ba})$.

$2.47 \%$ and $3.19 \%$ decreased RMSE $_{\text {rel }}$ in the low and the high peak, respectively.

Figure 8 shows $100 \mathrm{kVp}$ spectra filtered with $0.8654 \mathrm{~g} / \mathrm{cm}^{2}$ $\mathrm{Ce}$ and $0.7700 \mathrm{~g} / \mathrm{cm}^{2} \mathrm{Ba}$. The low peak of $\mathrm{Ba}$ is narrower than the low peak of $\mathrm{Ce}$, while the total number of counts in $\mathrm{CeO}_{2}$ filtration was 9.46 times higher in the low peak.

Table 5 summarizes the ranges of mean energies of the substances used in each technique (dual- or single-kVp) and the $\mathrm{kVps}$. In dual-kVp technique, the mean energies of the low- and high-energy band ranged from 35.05 to $37.65 \mathrm{keV}$ and 48.16 to $56.89 \mathrm{keV}$, respectively, while for the single-kVp technique they ranged from 34.01 to $39.13 \mathrm{keV}$ and 63.93 to 
TABLE 5: Summarized mean energy values for both exposure techniques.

\begin{tabular}{|c|c|c|c|c|c|}
\hline \multirow[t]{2}{*}{ Technique } & \multirow[t]{2}{*}{ Substance } & \multirow[t]{2}{*}{$\mathrm{kVp}$} & \multirow[t]{2}{*}{$\begin{array}{l}\text { Thickness } \\
\quad(\mu \mathrm{m})\end{array}$} & \multicolumn{2}{|c|}{$\begin{array}{c}\text { Mean energy range } \\
(\mathrm{keV})\end{array}$} \\
\hline & & & & Low energy & High energy \\
\hline \multirow{7}{*}{ Dual-kVp } & $\mathrm{CeO}_{2}$ & 60 & $100-1000$ & $35.05-37.65$ & - \\
\hline & & 70 & & - & $48.16-51.92$ \\
\hline & $\mathrm{Ho}_{2} \mathrm{O}_{3}$ & 80 & $500-1500$ & - & $49.12-52.10$ \\
\hline & & 90 & & - & $50.91-52.46$ \\
\hline & & 70 & & - & $50.39-55.56$ \\
\hline & $\mathrm{Yb}_{2} \mathrm{O}_{3}$ & 80 & $500-1500$ & - & $52.15-56.38$ \\
\hline & & 90 & & - & $53.87-56.89$ \\
\hline \multirow{6}{*}{ Single-kVp } & & 80 & & $37.72-39.12$ & $68.39-73.27$ \\
\hline & $\mathrm{CeO}_{2}$ & 90 & $1000-2500$ & $37.75-39.12$ & $74.69-81.02$ \\
\hline & & 100 & & $37.75-39.13$ & $80.74-88.36$ \\
\hline & & 80 & & $34.01-35.49$ & $63.93-69.54$ \\
\hline & $\mathrm{BaCl}_{2}\left(\mathrm{H}_{2} \mathrm{O}\right)_{2}$ & 90 & $1000-2500$ & $34.05-35.51$ & $68.82-70.06$ \\
\hline & & 100 & & $34.08-35.52$ & $73.43-82.34$ \\
\hline
\end{tabular}

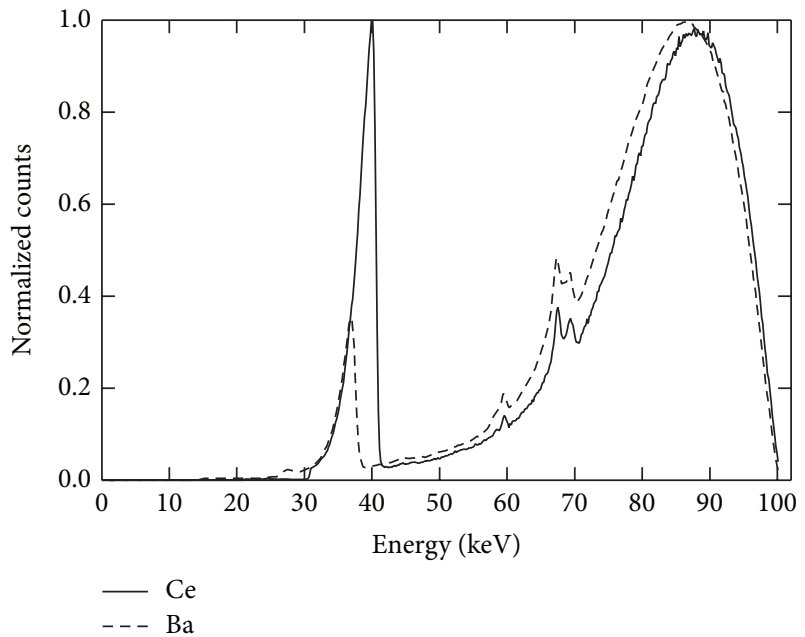

FIGURE 8: High-energy spectra at $100 \mathrm{kVp}$ filtered with $0.8654 \mathrm{~g} / \mathrm{cm}^{2}$ $\mathrm{Ce}$ and $0.7700 \mathrm{~g} / \mathrm{cm}^{2} \mathrm{Ba}(1300 \mu \mathrm{m}$ Ce and $2200 \mu \mathrm{m} \mathrm{Ba})$.

$88.16 \mathrm{keV}$ for the low- and high-energy band, respectively. This wide range, especially in high energy, indicates that these spectra could be used in several X-ray applications that are of interest in these energies, such as dual energy mammography and dual energy X-ray absorptiometry or even the mass calcium to phosphorus ratio determination in biological hydroxyapatite [4-6, 29].

$\mathrm{RMSE}_{\text {rel }}$ values are plotted as a function of areal density for all filters used in the dual-kVp technique and are shown in Figures 9, 10, and 11 corresponding to 70, 80, and $90 \mathrm{kVp}$. It can be seen that, at 70 and $80 \mathrm{kVp}$, both filters had the same impact on the spectral width, over all areal density ranges. On the contrary, at $90 \mathrm{kVp}$, Yb minimizes the $\mathrm{RMSE}_{\text {rel }}$ over all areal density ranges, since the K-edge absorption energy of $\mathrm{Yb}$ is higher than the K-edge of Ho filter.

Furthermore, for the single-kVp technique, the RMSE $\mathrm{rel}_{\text {rel }}$ values are plotted as a function of areal density for all filters

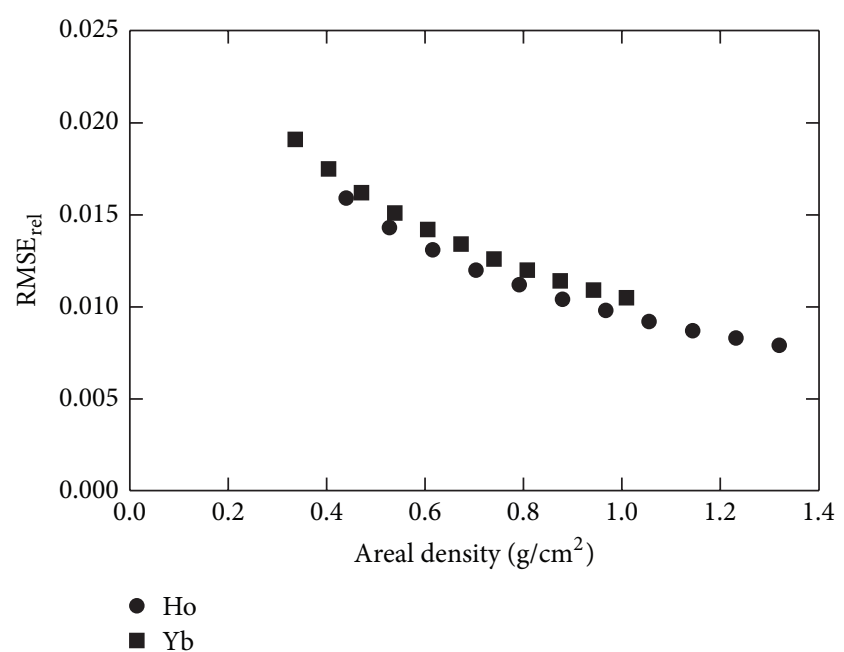

FIGURE 9: RMSE $\mathrm{E}_{\text {rel }}$ values as a function of areal density for all filters used in the dual-kVp technique at $70 \mathrm{kVp}$.

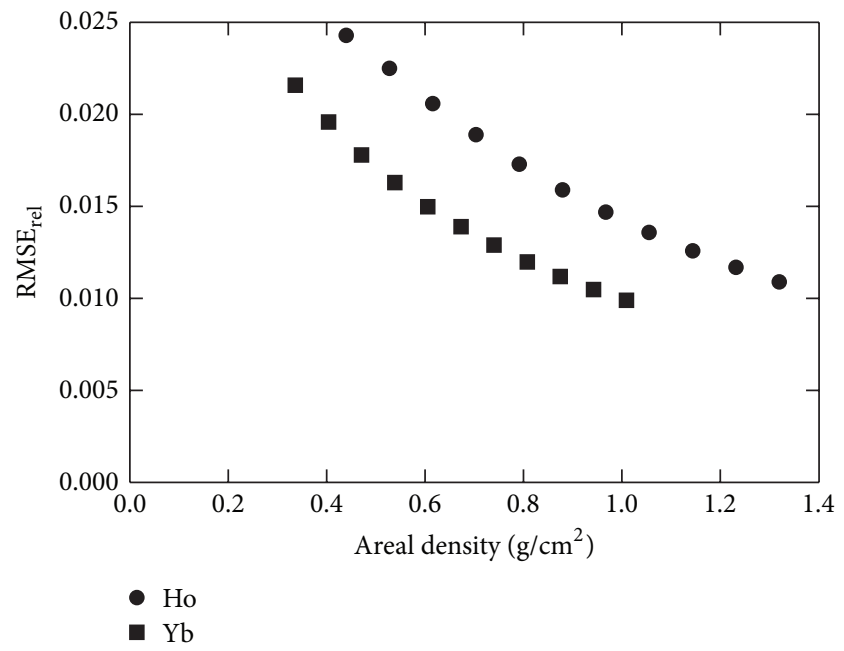

FIGURE 10: RMSE ${ }_{\text {rel }}$ values as a function of areal density for all filters used in the dual-kVp technique at $80 \mathrm{kVp}$. 


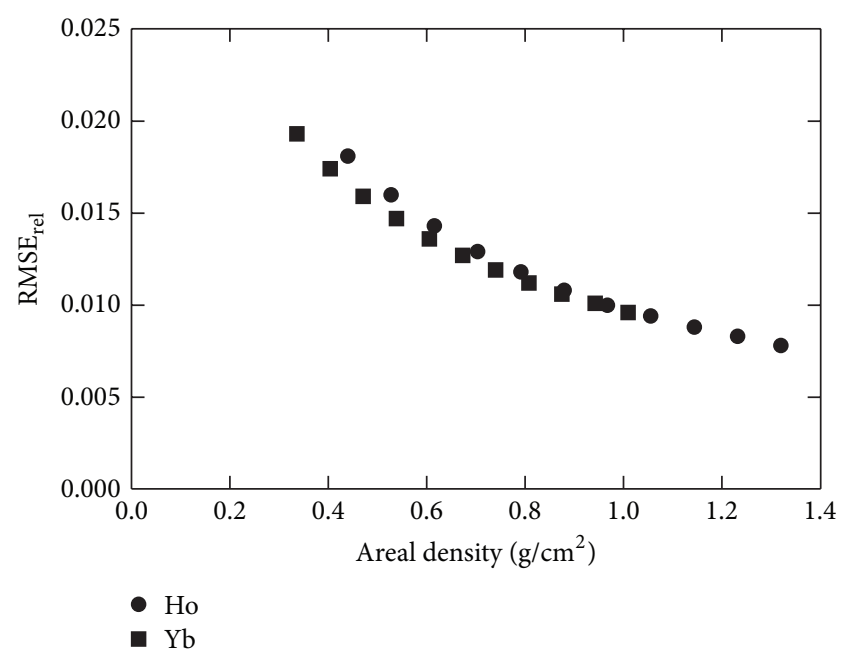

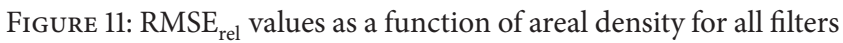
used in the dual-kVp technique at $90 \mathrm{kVp}$.

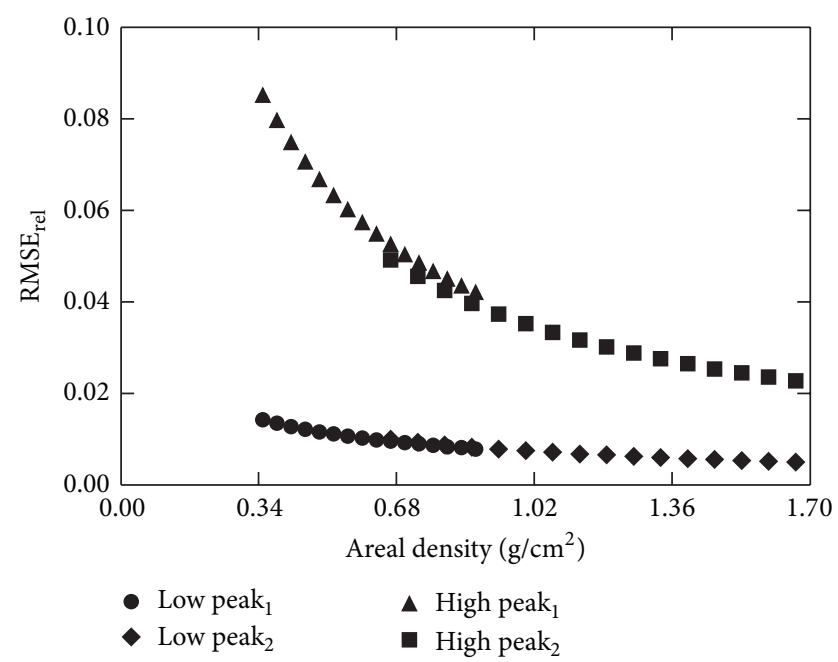

FIGURE 12: RMSE $\mathrm{rel}_{\text {rel }}$ values as a function of areal density for all filters used in the single- $\mathrm{kVp}$ technique at $80 \mathrm{kVp}$ (subscript 1 referred to $\mathrm{Ba}$ and 2 to $\mathrm{Ce}$ ).

tested shown in Figures 12, 13, and 14, corresponding to 80, 90 , and $100 \mathrm{kVp}$. As the areal density increases, lower $\mathrm{RMSE}_{\text {rel }}$ values of the high-energy peak indicate that narrower beams can be obtained by using either $\mathrm{Ce}$ or $\mathrm{Ba}$ filter materials. Similar results were observed in previous studies $[12,14]$.

Using narrow energy X-ray beams, instead of wide energy $\mathrm{X}$-rays, has several advantages in medical applications. Generally, in X-ray tubes inherent and added filtration is used to suppress the low-energy portion of the spectra. Low energies contribute to radiation dose, which increases the probability of cancer. Therefore, dose reduction at X-ray applications, that is, X-ray mammography, computed mammotomography, and computed tomography, would benefit the patients. Furthermore, using narrow beams, in dual energy techniques, is expected to improve separation of tissues with very small differences in attenuation coefficients or possibly the ability

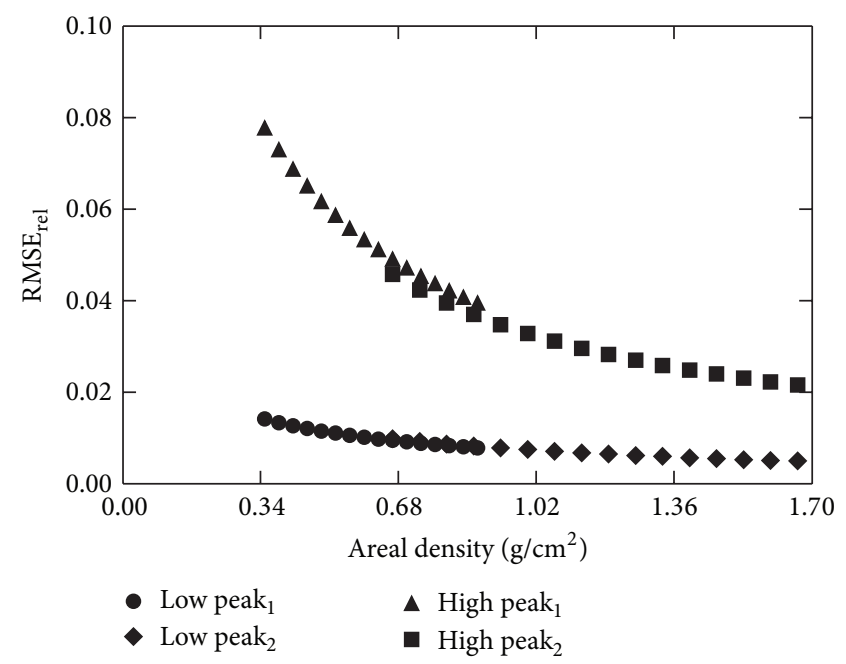

FIGURE 13: RMSE $_{\text {rel }}$ values as a function of areal density for all filters used in the single-kVp technique at $90 \mathrm{kVp}$ (subscript 1 referred to $\mathrm{Ba}$ and 2 to $\mathrm{Ce}$ ).

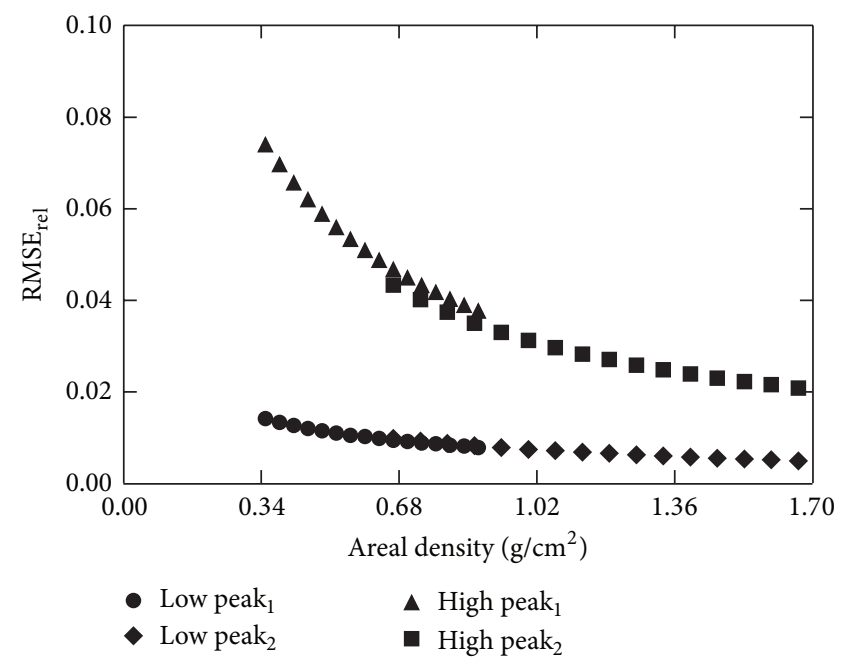

FIGURE 14: RMSE $\mathrm{rel}_{\text {rel }}$ values as a function of areal density for all filters used in the single- $\mathrm{kVp}$ technique at $100 \mathrm{kVp}$ (subscript 1 referred to $\mathrm{Ba}$ and 2 to $\mathrm{Ce})$.

of noninvasive tissue characterization [3, 12-14, 29]. Also, imaging with narrow energy spectra provides lower scatter noise and as a result beneficial influence on image contrast and signal-to-noise ratio $[2,13,14]$. Heavy K-edge filtering used in this study indicated that elimination of low-energy photons was accomplished for both dual- and single-kVp techniques, leading to narrow energy bands. However, this technique reduces photon influence, (value layers in Table 1), and thus higher output X-ray tubes are required.

The spectra presented here for the dual-kVp technique can be used in imaging techniques, while the spectra for the single-kVp technique can be used in quantitative bone densitometry measurements and imaging using silicon strip photon counting detectors [30]. 
Mean energy range of the spectra was in the diagnostic Xray energy range indicating that these spectra could be useful in various medical applications such as mammography, computed mammotomography, angiography, and DEXA.

\section{Conclusions}

In the present study, pencil X-ray beams were measured and filtered with different filter materials. K-edge filtering was implemented in order to obtain narrow energy bands for both dual- and single-kVp techniques. The increasing filter thickness resulted in narrowing of the spectral energy band, while on the contrary the total number of photons decreased. The X-ray tube voltages used in this work ranged from 60 to $100 \mathrm{kVp}$ providing higher mean beam energies. The resulting mean energies, after filtration, indicate that these $\mathrm{X}$-ray spectra could be used in various X-ray applications, such as dual energy mammography and absorptiometry and digital tomosynthesis improving their efficiency.

\section{Conflict of Interests}

The authors declare that there is no conflict of interests regarding the publication of this paper.

\section{Acknowledgments}

This research has been cofunded by the European Union (European Social Fund) and Greek national resources under the framework of the "Archimedes III: Funding of Research Groups in TEI of Athens" project of the "Education and Lifelong Learning” Operational Programme.

\section{References}

[1] R. Jonson, B. Roos, and T. Hansson, "Bone mineral measurement with a continuous roentgen ray spectrum and a germanium detector," Acta Radiologica: Diagnosis, vol. 27, no. 1, pp. 105-109, 1986.

[2] M. R. Lemacks, S. C. Kappadath, C. C. Shaw, X. Liu, and G. J. Whitman, "A dual-energy subtraction technique for microcalcification imaging in digital mammography-a signal-to-noise analysis," Medical Physics, vol. 29, no. 8, pp. 1739-1751, 2002.

[3] G. Fountos, S. Yasumura, and D. Glaros, "The skeletal calcium/phosphorus ratio: a new in vivo method of determination," Medical Physics, vol. 24, no. 8, pp. 1303-1310, 1997.

[4] V. Koukou, N. Martini, G. Fountos et al., "Calcification detection optimization in dual energy mammography: influence of the X-ray spectra," in XIII Mediterranean Conference on Medical and Biological Engineering and Computing 2013: MEDICON 2013, 25-28 September 2013, Seville, Spain, vol. 41 of IFMBE Proceedings, pp. 459-462, Springer International Publishing, Cham, Switzerland, 2014.

[5] P. Sotiropoulou, G. Fountos, N. Martini et al., "X-ray spectra for bone quality assessment using energy dispersive counting and imaging detectors with dual energy method," in XIII Mediterranean Conference on Medical and Biological Engineering and Computing 2013, vol. 41 of IFMBE Proceedings, pp. 463-466, Springer, 2014.
[6] V. Koukou, N. Martini, P. Sotiropoulou et al., "Modified polyenergetic X-ray spectra for dual energy method," e-Journal of Science \& Technology, vol. 7, no. 3, pp. 79-85, 2012.

[7] B. Jacobson, "Development of dichromography techniques," Final Progress Report, Grant no. 5, The National Institute of Arthritis and Metabolic Diseases, 1968.

[8] B. K. Rutt, "Optimized KVP filtration and detection parameters for dual energy imaging," Medical Physics, vol. 2, no. 536, 1985.

[9] K. Reiss, K. Killig, and W. Schuster, "Dual photon x-ray beam applications," in Proceedings of the International Conference on Bone Mineral Measurement, R. Mazess, Ed., pp. 80-87, 1973.

[10] J. A. Sorenson, P. R. Duke, and S. W. Smith, "Simulation studies of dual-energy x-ray absorptiometry," Medical Physics, vol. 16, no. 1, pp. 75-80, 1989.

[11] L. Gustafsson, B. Jacobson, and L. Kusoffsky, "X-ray spectrophotometry for bone mineral determinations," Medical and Biological Engineering, vol. 12, no. 1, pp. 113-119, 1974.

[12] D. J. Crotty, R. L. McKinley, and M. P. Tornai, "Experimental spectral measurements of heavy $K$-edge filtered beams for $\mathrm{x}$ ray computed mammotomography," Physics in Medicine and Biology, vol. 52, no. 3, pp. 603-616, 2007.

[13] R. L. McKinley, M. P. Tornai, E. Samei, and M. L. Bradshaw, "Simulation study of a quasi-monochromatic beam for x-ray computed mammotomography," Medical Physics, vol. 31, no. 4, pp. 800-813, 2004.

[14] S. J. Glick, S. Thacker, X. Gong, and B. Liu, "Evaluating the impact of X-ray spectral shape on image quality in flat-panel CT breast imaging," Medical Physics, vol. 34, no. 5, pp. 5-24, 2007.

[15] C. M. Michail, N. E. Kalyvas, I. G. Valais et al., "Figure of image quality and information capacity in digital mammography," BioMed Research International, vol. 2014, Article ID 634856, 11 pages, 2014.

[16] T. R. Fewell and R. E. Shuping, "Photon energy distribution of some typical diagnostic x-ray beams," Medical Physics, vol. 4, no. 3, pp. 187-197, 1977.

[17] R. Birch and M. Marshall, "Computation of bremsstrahlung $\mathrm{X}$-ray spectra and comparison with spectra measured with a $\mathrm{Ge}(\mathrm{Li})$ detector," Physics in Medicine and Biology, vol. 24, no. 3, pp. 505-517, 1979.

[18] K. Aoki and M. Koyama, "Measurement of diagnostic x-ray spectra using a silicon photodiode," Medical Physics, vol. 16, no. 4, pp. 529-536, 1989.

[19] A. R. Chourasia, J. L. Hickman, R. L. Miller, G. A. Nixon, and M. A. Seabolt, "X-ray photoemission study of the oxidation of hafnium," International Journal of Spectroscopy, vol. 2009, Article ID 439065, 6 pages, 2009.

[20] S. Miyajima, K. Imagawa, and M. Matsumoto, "CdZnTe detector in diagnostic X-ray spectroscopy," Medical Physics, vol. 29, no. 7, pp. 1421-1429, 2002.

[21] S. Miyajima, "Thin CdTe detector in diagnostic x-ray spectroscopy," Medical Physics, vol. 30, no. 5, pp. 771-777, 2003.

[22] S. Stumbo, U. Bottigli, B. Golosio, P. Oliva, and S. Tangaro, "Direct analysis of molybdenum target generated x-ray spectra with a portable device," Medical Physics, vol. 31, no. 10, pp. 27632770, 2004.

[23] C. M. Michail, V. A. Spyropoulou, G. P. Fountos et al., "Experimental and theoretical evaluation of a high resolution CMOS based detector under X-ray imaging conditions," IEEE Transactions on Nuclear Science, vol. 58, no. 1, pp. 314-322, 2011. 
[24] C. M. Michail, G. P. Fountos, I. G. Valais et al., "Evaluation of the red emitting $\mathrm{Gd}_{2} \mathrm{O}_{2} \mathrm{~S}$ : Eu powder scintillator for use in indirect $\mathrm{X}$-ray digital mammography detectors," IEEE Transactions on Nuclear Science, vol. 58, no. 5, pp. 2503-2511, 2011.

[25] I. E. Seferis, C. M. Michail, I. G. Valais et al., "On the response of a europium doped phosphor-coated CMOS digital imaging detector," Nuclear Instruments and Methods in Physics Research Section A: Accelerators, Spectrometers, Detectors and Associated Equipment, vol. 729, pp. 307-315, 2013.

[26] L. Abbene, A. La Manna, F. Fauci, G. Gerardi, S. Stumbo, and G. Raso, "X-ray spectroscopy and dosimetry with a portable CdTe device," Nuclear Instruments and Methods in Physics Research Section A: Accelerators, Spectrometers, Detectors and Associated Equipment, vol. 571, no. 1-2, pp. 373-377, 2007.

[27] Amptek, X-Ray \& Gamma Ray Detector, XR-100T-CdTe [Internet], Amptek, Bedford, Mass, USA, 2014, http://www.amptek .com/xr100cdt.html.

[28] G. P. Fountos, C. M. Michail, A. Zanglis et al., "A novel easy-touse phantom for the determination of MTF in SPECT scanners," Medical Physics, vol. 39, no. 3, pp. 1561-1570, 2012.

[29] G. Fountos, M. Tzaphlidou, E. Kounadi, and D. Glaros, "In vivo measurement of radius calcium/phosphorus ratio by $\mathrm{x}$-ray absorptiometry," Applied Radiation and Isotopes, vol. 51, no. 3, pp. 273-278, 1999.

[30] W. Barber, J. Wessel, N. Malakhov et al., "Energy dispersive photon counting detectors for breast imaging," in Medical Applications of Radiation Detectors III, vol. 8853 of Proceedings of SPIE, September 2013. 

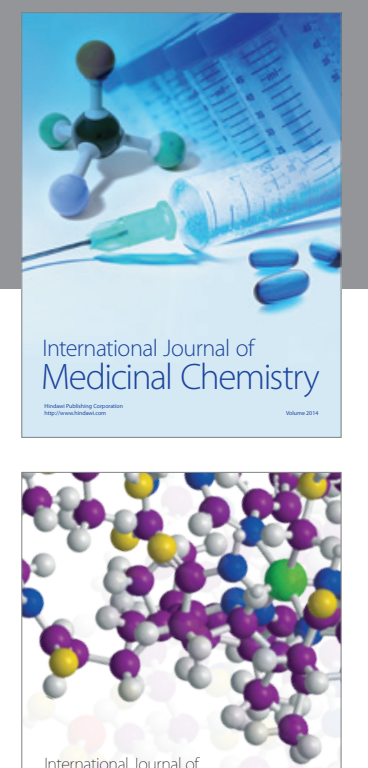

\section{Carbohydrate} Chemistry

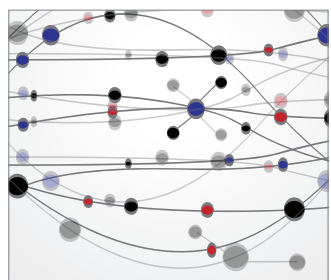

The Scientific World Journal
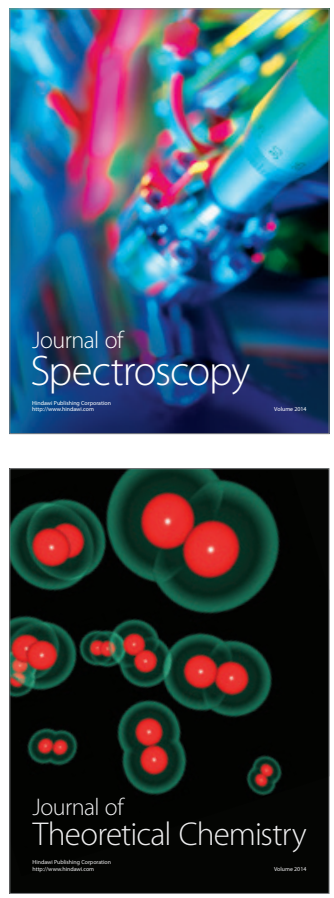
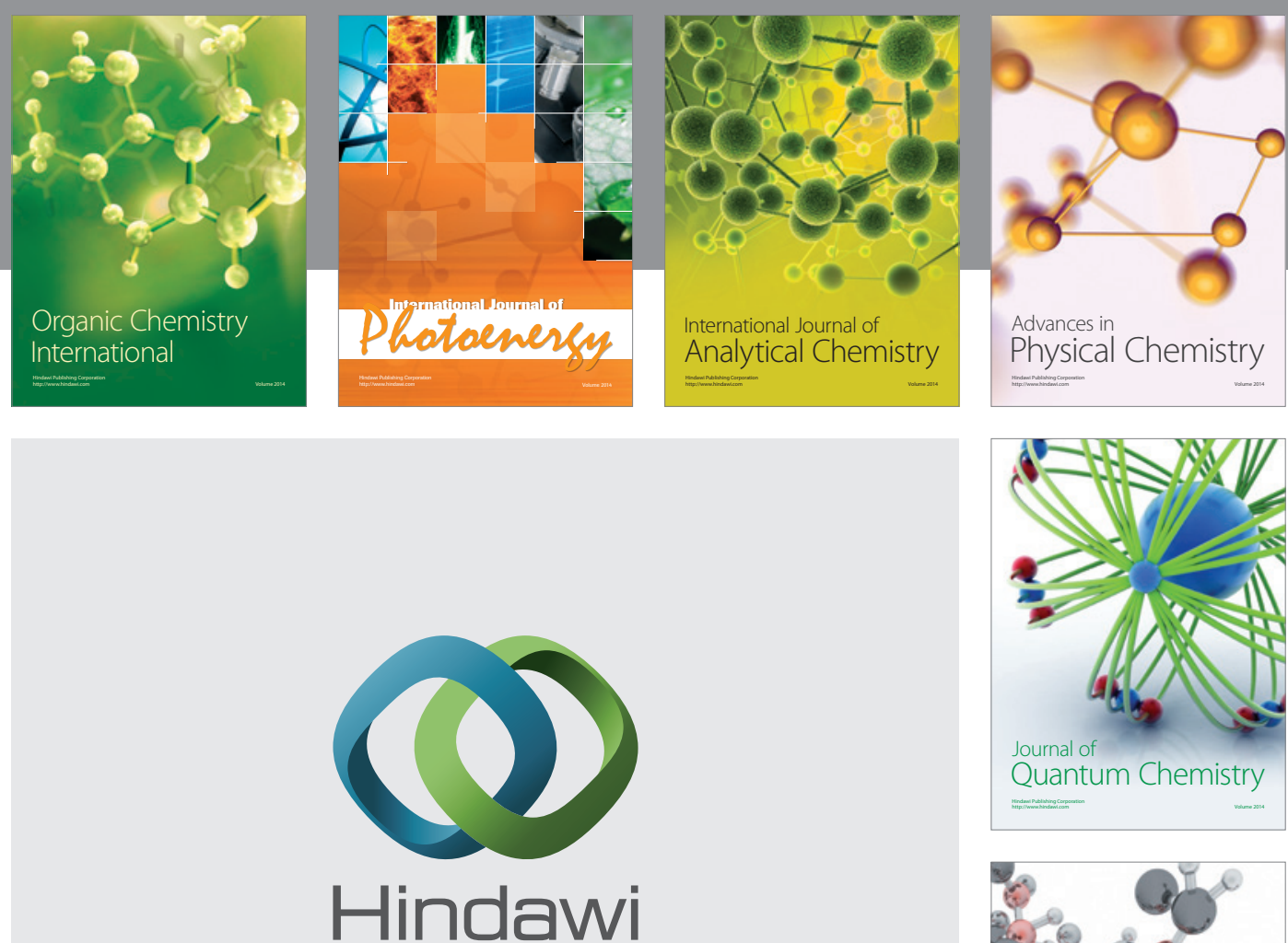

Submit your manuscripts at

http://www.hindawi.com

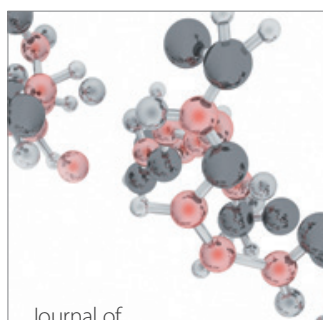

Analytical Methods

in Chemistry

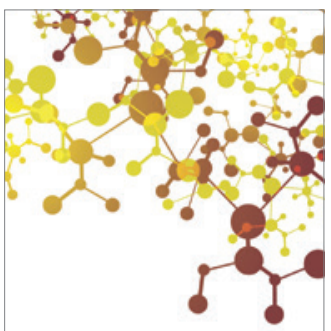

Journal of

Applied Chemistry

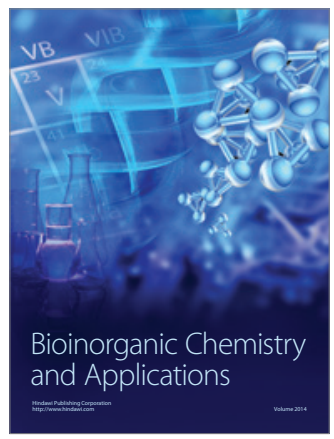

Inorganic Chemistry
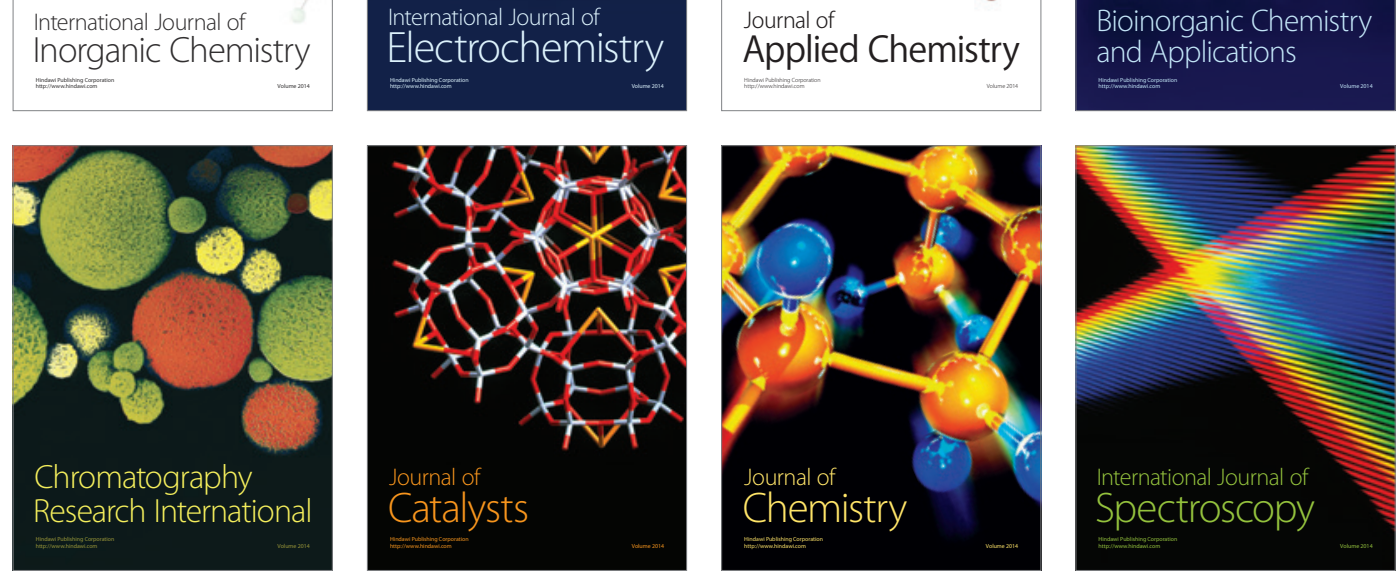